\title{
Early-onset Crohn's disease is a risk factor for smaller final height
}

\author{
Denise Herzog ${ }^{a}$, Nicolas Fournier ${ }^{b}$, Patrick Buehr ${ }^{d}$, Rebekka Koller ${ }^{d}$, \\ $V$ anessa Rueger ${ }^{d}$, Klaas Heyland ${ }^{d}$, Andreas Nydegger ${ }^{c}$, Johannes Spalinger ${ }^{f}$, \\ Susanne Schiblig and Christian Braegger ${ }^{\mathrm{d}, \mathrm{e}}$; On behalf of the Swiss IBD Cohort \\ Study Group
}

\begin{abstract}
Objectives Growth retardation is a frequent complication of paediatric inflammatory bowel disease (IBD). Only a few studies report the final height of these patients, with controversial results. We compared adult height of patients with paediatric IBD with that of patients with adult-onset disease.
\end{abstract}

Methods Height data of 675 women 19-44 years of age and 454 men 23-44 years of age obtained at inclusion in the Swiss IBD cohort study registry were grouped according to the age at diagnosis: (a) prepubertal (men $\leq 13$, women $\leq 11$ years), (b) pubertal (men 13-22, women 11-18 years) and (c) adult (men $>22$, women $>18$ years of age), and compared with each other and with healthy controls.

Results Male patients with prepubertal onset of Crohn's disease (CD) had significantly lower final height (mean $172 \pm 6 \mathrm{~cm}$, range 161-182) compared with men with pubertal $(179 \pm 6 \mathrm{~cm}, 161-192)$ or adult $(178 \pm 7 \mathrm{~cm}$, 162-200) age at onset and the general population $(178 \pm 7 \mathrm{~cm}, 142-204)$. Height $z$-scores standardized against heights of the normal population were significantly lower in all patients with a prepubertal diagnosis of CD $(-0.8 \pm 0.9)$ compared with the other patient groups $(-0.1 \pm 0.8, P<0.001)$. Prepubertal onset of $C D$ emerged as a risk factor for reduced final height in patients with prepubertal CD. No difference for final height was found between patients with ulcerative or unclassified IBD diagnosed at prepubertal, pubertal or adult age.

Conclusion Prepubertal onset of $C D$ is a risk for lower final height, independent of the initial disease location and the necessity for surgical interventions. Eur J Gastroenterol Hepatol 26:1234-1239 (c) 2014 Wolters Kluwer Health | Lippincott Williams \& Wilkins.

European Journal of Gastroenterology \& Hepatology 2014, 26:1234-1239

Keywords: final height, inflammatory bowel disease, paediatric, prepubertal, pubertal

aDepartment of Pediatrics, Division of Gastroenterology, Cantons Hospital of Fribourg, Fribourg, 'University Hospital of Lausanne, Institute of Social and Preventive Medicine, 'Division of Gastroenterology, University Children's Hospital of Lausanne, Lausanne, 'Division of Gastroenterology and Nutrition, ${ }^{\text {e}}$ Children's Research Center, University Children's Hospital Zurich, Zurich, 'Division of Gastroenterology, Children's Hospital of Lucerne, Lucerne and 9Division of Gastroenterology, University Children's Hospital of Bern, Bern, Switzerland

Correspondence to Christian P. Braegger, MD, Division of Gastroenterology and Nutrition, University Children's Hospital, Steinwiesstrasse 75, CH-8032 Zurich, Switzerland

Tel: + 414426673 23; fax: + 41442667171 ;

e-mail: christian.braegger@kispi.uzh.ch

Received 13 April 2014 Accepted 24 June 2014

linear growth over a minimum of 6 months $[5,6]$. However, a recent Spanish study on growth including 32064 normal individuals measured increasing height up to the age of 24 years, and the median growth between 18 and 24 years was $1.33 \mathrm{~cm}$ in men and $0.01 \mathrm{~cm}$ in women [10], a finding that challenges former definitions of final height. Thus, we hypothesized that, if final height is measured during early adulthood, patients with prepubertal disease onset would be found to have a smaller adult height than patients with later disease onset. Thus, the aim of the study was to compare the final height of IBD patients diagnosed during childhood with that of patients diagnosed during adulthood and to healthy controls. For this purpose, we analysed data collected in a nationwide multicentre cohort study on patients with IBD, the Swiss IBD cohort study, that was initiated in 2006 by the University of Lausanne [11]. 


\section{Patients and methods}

As of November, 2012, 2069 patients diagnosed with CD, ulcerative colitis (UC) or IBD-unclassified (IU) according to standard criteria [12], included at least 4 months after diagnosis, were registered in the Swiss IBD cohort study database. The study protocol for this registry had been approved by the central and the local ethics committees in 2006. As described by Pittet et al. [11], patient inclusion was performed by the following six university centres from western through eastern Switzerland: Geneva, Lausanne, Bern, Basel, Zurich and St Gallen, with the University of Lausanne as the coordinating centre and database location. We retrieved the two types of data from the registry: (a) information obtained from the patient chart at the time of enrolment, such as date of birth, sex, age at inclusion, age at IBD diagnosis, type of IBD (CD, UC, IU), disease location recorded according to Montreal classification [13], after verification of a work up according to inclusion criteria, and the necessity for surgery, defined as the sum of resectional and minor perianal surgery, excluding non-IBD-related surgeries, the cumulative use of corticosteroids and biologic agents, and (b) measured information, such as height and weight measured by the study nurse at the visit of enrolment using the wall stadiometers and weight scales available at the various study centres. Data of controls were obtained from the Federal Office of Public Health survey of 2007 [14]. For patients' inclusion, see the flow diagram shown in Fig. 1.

\section{Statistics}

Continuous data distribution was assessed using NormalQQ-plots. Gaussian distributed data were presented as mean $\pm \mathrm{SD}$ and range, and non-Gaussian distributed data were presented as median, interquartile range and range. Differences in continuous data distribution between two groups were assessed using Student's $t$-test in case of
Gaussian data or using the Wilcoxon-Mann-Whitney rank sum test in case of non-Gaussian data. Differences in continuous data distribution between more than two groups were assessed using Fisher's $F$-test in case of Gaussian data or using the Kruskall-Wallis test in case of non-Gaussian data. Categorical data were presented as raw count and relative percentages. Differences in categorical data distribution between groups were assessed using the $\chi^{2}$-test or Fisher's exact test in case of insufficient sample size. Simple linear regression was used to assess the effects of several factors on adult standardized height. Age category for disease onset, disease location at diagnosis and history of surgery were used as predictors for each sex and each disease separately. For the purpose of this study, a $P$-value less than 0.05 was considered statistically significant. Bonferroni's correction was applied in case of multiple testing.

\section{Results}

Male CD patients with prepubertal disease onset had a significantly lower final height than patients diagnosed at pubertal or adult age and the male Swiss population. The diagnosis was made before 1980 in two (final height $170 \mathrm{~cm}$, both), between 1980 and 1989 in six (168, $2 \times 170,171,179,182 \mathrm{~cm})$ and between 1990 and 1997 in eight patients (161, 163, 164, 171, 173, 175, 181, $184 \mathrm{~cm})$. Seven female patients had prepubertal onset of CD (diagnosis between 1980 and 1989 in four, final height $160 \times 2,164,173 \mathrm{~cm}$, and between 1990 and 1994 in three, final height 143,160,165 cm) and their final height was not significantly smaller than that of the patients of any other group. The number of UC/IU patients with prepubertal disease onset was too small for analysis. There was no difference for final height in $\mathrm{UC} / \mathrm{IU}$ patients with pubertal disease compared with that of patients with adult-onset disease or the Swiss population (Table 1). After standardization of the final

Fig. 1

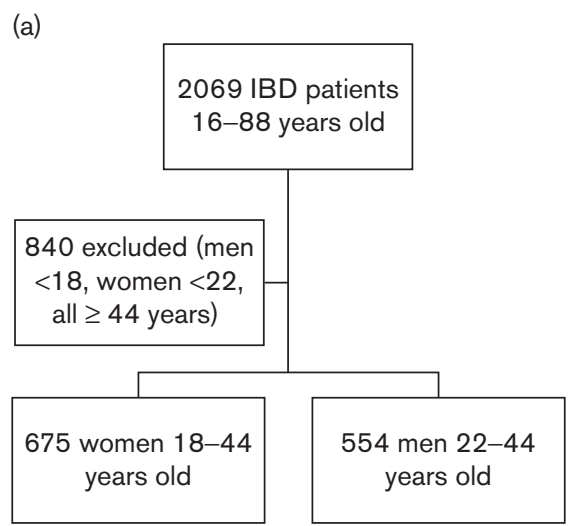

(b)

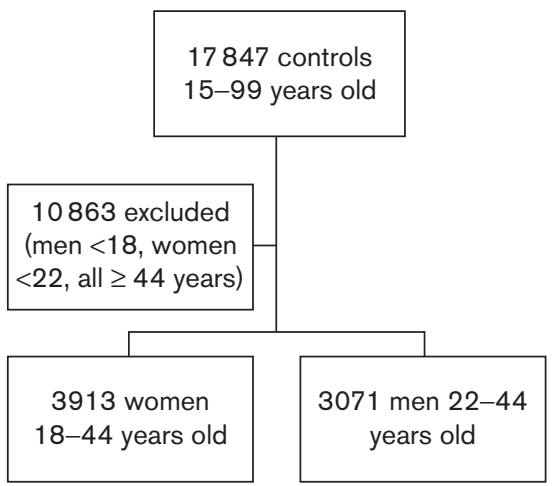

Flow diagram of patients included in our study: (a) patients enrolled into the registry of the Swiss IBD Cohort Study, (b) healthy individuals recruited by the Federal Office of Public Health in 2007 at the time of the public health survey. IBD, inflammatory bowel disease. 
Table 1 Final height of patients with IBD grouped according to the age at disease onset

\begin{tabular}{|c|c|c|c|c|c|c|c|c|c|c|c|}
\hline Disease onset & Prepubertal (pre) & $\begin{array}{l}\text { Pubertal } \\
\text { (pub) }\end{array}$ & Adult (adu) & $\begin{array}{c}\text { Healthy } \\
\text { controls (HC) }\end{array}$ & $\begin{array}{l}P \text {-value } \\
\text { overall }^{\mathrm{a}}\end{array}$ & Pre vs. pub ${ }^{b}$ & $\begin{array}{l}\text { Pre vs. } \\
\text { adu }^{b}\end{array}$ & $\begin{array}{l}\text { Pub vs. } \\
\text { adu }^{b}\end{array}$ & $\begin{array}{c}\text { Pre vs. } \\
\mathrm{HC}^{\mathrm{b}}\end{array}$ & $\begin{array}{c}\text { Pub vs. } \\
\mathrm{HC}^{\mathrm{b}}\end{array}$ & $\begin{array}{c}\text { Adu vs. } \\
\mathrm{HC}^{\mathrm{b}}\end{array}$ \\
\hline Male patients with CD & & & & & 0.001 & $<0.001$ & 0.001 & 0.134 & 0.001 & 0.331 & 0.235 \\
\hline Number of patients & 16 & 90 & 186 & 3071 & & & & & & & \\
\hline Height $(\mathrm{cm})$ & $172 \pm 6$ & $179 \pm 6$ & $178 \pm 7$ & $178 \pm 7$ & & & & & & & \\
\hline Mean $\pm S D$, range & $161-182$ & $161-192$ & $162-200$ & $142-204$ & & & & & & & \\
\hline $\begin{array}{l}\text { Female patients with } \\
\text { CD }\end{array}$ & & & & & 0.072 & 0.065 & 0.035 & 0.569 & 0.172 & 0.229 & 0.301 \\
\hline Number of patients & 7 & 87 & 320 & 3913 & & & & & & & \\
\hline Height $(\mathrm{cm})$ & $161 \pm 9$ & $165 \pm 6$ & $166 \pm 6$ & $166 \pm 6$ & & & & & & & \\
\hline Mean $\pm S D$, range & $143-173$ & $151-178$ & $152-183$ & $130-186$ & & & & & & & \\
\hline $\begin{array}{l}\text { Male patients with } \\
\text { UC/IU }\end{array}$ & & & & & 0.406 & 0.741 & 0.587 & 0.163 & 0.778 & 0.466 & 0.151 \\
\hline Number of patients & 2 & 68 & 192 & 3071 & & & & & & & \\
\hline Height $(\mathrm{cm})$ & $175 \pm 13$ & $179 \pm 6$ & $178 \pm 7$ & $178 \pm 7$ & & & & & & & \\
\hline Mean $\pm S D$, range & $166-184$ & $164-194$ & $160-197$ & $142-204$ & & & & & & & \\
\hline $\begin{array}{l}\text { Female patients with } \\
\text { UC/IU }\end{array}$ & & & & & 0.900 & 0.740 & 0.927 & 0.449 & 0.466 & 0.457 & 0.756 \\
\hline Number of patients & 2 & 27 & 232 & 3913 & & & & & & & \\
\hline Height $(\mathrm{cm})$ & $166 \pm 1$ & $167 \pm 6$ & $166 \pm 6$ & $166 \pm 6$ & & & & & & & \\
\hline Mean $\pm S D$, range & $165-166$ & $157-181$ & $150-185$ & $130-186$ & & & & & & & \\
\hline
\end{tabular}

$\mathrm{CD}$, Crohn's disease; IBD, inflammatory bowel disease; UC/IU, ulcerative colitis or IBD-unclassified.

${ }^{a}$ Fisher's F-test.

bStudent's $t$-test.

heights of patients against the heights of the coeval Swiss population, age classes could be compared independent of sexes, and all patients with prepubertal disease onset of $\mathrm{CD}$, but not $\mathrm{UC} / \mathrm{IU}$ had significantly smaller final heights (Table 2 and Fig. 2) than the other groups.
At disease onset and for both sexes together, ileal disease location was present in five prepubertal $(21.7 \%)$, in 31 pubertal $(17.5 \%)$ and in 116 adult $(22.9 \%)$, ileocolonic location was present in 12 prepubertal $(52.2 \%)$, in 96 pubertal $(54.2 \%)$ and in 237 adult $(46.8 \%)$, colonic

Table 2 Standardized final heights of patients with IBD, normalized against coeval healthy individuals, grouped according to the age group at disease onset, sex and disease type

\begin{tabular}{|c|c|c|c|c|c|c|c|c|c|c|c|}
\hline Disease onset & Prepubertal (pre) & Pubertal (pub) & Adult (adu) & $\begin{array}{c}\text { Healthy } \\
\text { controls (HC) }\end{array}$ & $\begin{array}{l}P \text {-value } \\
\text { overall }^{\mathrm{a}}\end{array}$ & Pre vs. pub ${ }^{b}$ & $\begin{array}{l}\text { Pre vs. } \\
\text { adu }^{b}\end{array}$ & $\begin{array}{l}\text { Pub vs. } \\
\text { adu }^{b}\end{array}$ & $\begin{array}{l}\text { Pre vs. } \\
\mathrm{HC}^{\mathrm{b}}\end{array}$ & $\begin{array}{l}\text { Pub vs. } \\
\mathrm{HC}^{\mathrm{b}}\end{array}$ & $\begin{array}{l}\text { Adu vs. } \\
\mathrm{HC}^{\mathrm{b}}\end{array}$ \\
\hline $\begin{array}{l}\text { Male patients with } \\
\text { CD }\end{array}$ & & & & & 0.001 & $<0.001$ & 0.002 & 0.111 & 0.001 & 0.332 & 0.189 \\
\hline Number of patients & 16 & 90 & 186 & 3071 & & & & & & & \\
\hline Standard height & $-0.8 \pm 0.7$ & $0.1 \pm 0.7$ & $-0.1 \pm 0.7$ & $0.0 \pm 0.8$ & & & & & & & \\
\hline Mean $\pm S D$, range & $-2.1-0.4$ & $-2.1-1.5$ & $-2.0-2.3$ & $-3.8-2.7$ & & & & & & & \\
\hline $\begin{array}{l}\text { Female patients with } \\
\text { CD }\end{array}$ & & & & & 0.023 & 0.276 & 0.199 & 0.249 & 0.170 & 0.061 & 0.259 \\
\hline Number of patients & 7 & 87 & 320 & 3913 & & & & & & & \\
\hline Standard height & $-0.8 \pm 1.2$ & $-0.2 \pm 0.8$ & $-0.1 \pm 0.8$ & $0.0 \pm 0.8$ & & & & & & & \\
\hline Mean $\pm S D$, range & $-3.1-0.9$ & $-2.0-1.4$ & $-2.0-2.0$ & $-4.4-2.5$ & & & & & & & \\
\hline $\begin{array}{l}\text { Male patients with } \\
\text { UC/IU }\end{array}$ & & & & & 0.375 & 0.734 & 0.804 & 0.190 & 0.763 & 0.542 & 0.136 \\
\hline Number of patients & 2 & 68 & 192 & 3071 & & & & & & & \\
\hline Standard height & $-0.4 \pm 1.5$ & $0.0 \pm 0.7$ & $-0.1 \pm 0.7$ & $0.0 \pm 0.8$ & & & & & & & \\
\hline Mean $\pm S D$, range & $-1.5-0.7$ & $-1.5-1.8$ & $-2.3-2.0$ & $-3.8-2.7$ & & & & & & & \\
\hline $\begin{array}{l}\text { Female patients with } \\
\text { UCIIU }\end{array}$ & & & & & 0.977 & 0.334 & 0.406 & 0.734 & 0.428 & 0.795 & 0.793 \\
\hline Number of patients & 2 & 27 & 232 & 3913 & & & & & & & \\
\hline Standard height & $-0.2 \pm 0.2$ & $0.0 \pm 0.8$ & $0.0 \pm 0.8$ & $0.0 \pm 0.8$ & & & & & & & \\
\hline Mean $\pm S D$, range & $-0.3-0.1$ & $-1.3-1.7$ & $-2.2-2.5$ & $-4.4-2.5$ & & & & & & & \\
\hline All patients with CD & & & & & $<0.001$ & 0.001 & 0.001 & 0.760 & 0.001 & 0.480 & 0.086 \\
\hline Number of patients & 23 & 177 & 506 & 6983 & & & & & & & \\
\hline Standard height & $-0.8 \pm 0.9$ & $-0.1 \pm 0.8$ & $-0.1 \pm 0.8$ & $0.0 \pm 0.8$ & & & & & & & \\
\hline Mean $\pm S D$, range & $-3.1-0.9$ & $-2.1-1.5$ & $-2.0-2.3$ & $-4.4-2.7$ & & & & & & & \\
\hline $\begin{array}{l}\text { All patients with } \\
\text { UC/IU }\end{array}$ & & & & & 0.515 & 0.504 & 0.626 & 0.245 & 0.568 & 0.478 & 0.258 \\
\hline Number of patients & 4 & 95 & 424 & 6983 & & & & & & & \\
\hline Standard height & $-0.3 \pm 0.9$ & $0.0 \pm 0.7$ & $-0.1 \pm 0.8$ & $0.0 \pm 0.8$ & & & & & & & \\
\hline Mean $\pm S D$, range & $-1.5-0.7$ & $-1.5-1.8$ & $-2.3-2.5$ & $-4.4-2.7$ & & & & & & & \\
\hline
\end{tabular}

CD, Crohn's disease; IBD, inflammatory bowel disease; UC/IU, ulcerative colitis or IBD-unclassified.

${ }^{\text {a}}$ Fisher's F-test.

${ }^{\text {b}}$ Student's $t$-test. 
Fig. 2

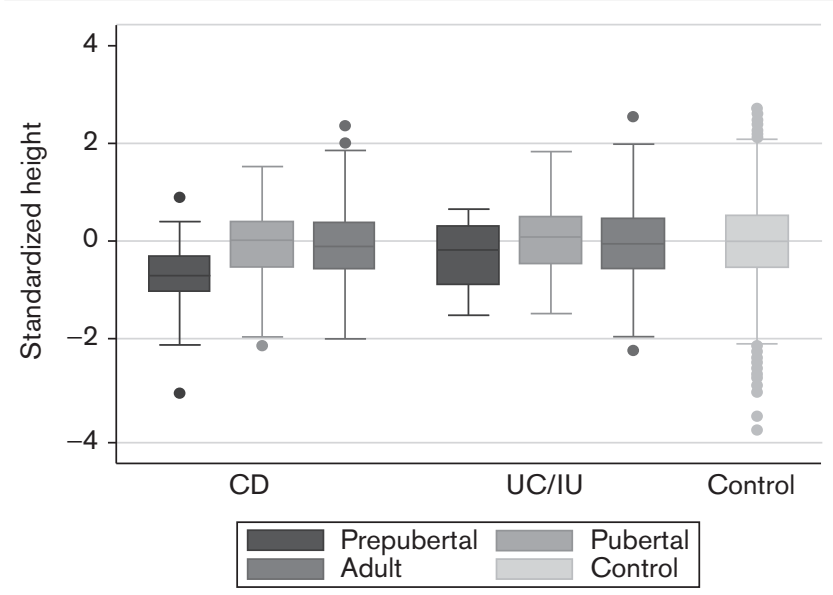

Comparison of standardized final heights of patients with CD or UC/IU and disease onset at prepubertal, pubertal or adult ages. CD, Crohn's disease; UC/IU, ulcerative colitis or inflammatory bowel diseaseunclassified.

location was present in one prepubertal (4.4\%), in 30 pubertal (17.0\%), and in 117 adult (23.1\%), and unknown location in $5(21.7 \%)$ prepubertal, in $19(10.7 \%)$ pubertal and in $31(6.1 \%)$ adult patients. The difference of unknown locations makes up for the significant difference between age groups.

Perineal and resectional surgical interventions in patients with $\mathrm{CD}$ of both sexes were required in 18 with prepubertal $(78.3 \%)$, in 93 with pubertal $(52.5 \%)$ and in with 193 adult-onset $(38.1 \%)$ disease $(P<0.05$ for each comparison), and in $0 \%$ with prepubertal, in nine with pubertal $(9.5 \%)$ and in 21 with adult-onset $(5 \%)$ disease of $\mathrm{UC} / \mathrm{IU}(P=\mathrm{NS}$ for each comparison).

Univariate regression analysis enabled exclusion of factors such as the necessity for surgery or the initial disease location such as predictors of final height, and age at diagnosis emerged as the only predictive factor for final height (Table 3).

Corticosteroid therapy administered before study entry was recorded in $68 \%$ male and $86 \%$ female patients with prepubertal, in $50 \%$ male and $47 \%$ female patients with pubertal and in $45.7 \%$ male and $44 \%$ female patients with adult onset of $\mathrm{CD}$ ( $P=\mathrm{NS}$ between all groups), in $48 \%$ male and $59 \%$ female patients with pubertal and in $33.3 \%$ male and $42 \%$ female patients with adult onset of UC or unclassified colitis. Corticosteroid consumption during growth was not available as cumulative dose per kilo body weight. Infliximab, authorized for in 1999 for adult and in 2007 for patients 6-17 years of age, was administered in $12.5 \%$ male and $0 \%$ female patients with prepubertal, in $4.4 \%$ male and $16.1 \%$ female patients with pubertal and in $9.6 \%$ male $10.6 \%$ female patients with adult onset of $\mathrm{CD}$, in
9.4\% male and $3.7 \%$ female with pubertal, in $4.2 \%$ male and $2.6 \%$ female patients with adult-onset UC/IU.

\section{Discussion}

With this study, we could clearly show that final height in patients diagnosed with CD before the beginning of the pubertal growth spurt, that is before 13 years in males and 11 years in females, is significantly smaller than that of patients with later disease onset. Only a few reports have assessed the final adult height in IBD patients with paediatric onset disease [4-9]. Prospective studies mostly included paediatric patients up to the age of 18 years $[4,5]$, and retrospective studies carried out in adult patients either analyse patients with CD diagnosed before the age of 16 or 17 years [7,8] as a single group, patients with $\mathrm{UC}$ and $\mathrm{CD}$ as a mixed group [1,9] or report height measures collected by telephone or from passports [4]. In this study, we have separately analysed patients with either UC/IU or CD and with either prepubertal, pubertal or adult-onset disease, and we have compared measured and dated final height of patients with prepubertal disease onset with that of patients with pubertal or adult disease onset and with that of healthy controls. Our age groups were constituted according to the tables of Tanner and Whitehouse [15], where the median age at onset of pubertal growth spurt is 13 years in boys and 11 years in girls, according to data of the Spanish cohort [10] for the age of achievement of final height and data of multiple reports $[16,17]$ for the beginning of significant height loss during adult life. It is noteworthy that the cutoff of less than 17 years for paediatric age used by the Montreal classification is based on the need for a pediatric age group and the cutoff of less than 10 years of age proposed by the Paris classification on the different clinical and serologic phenotypes of $\mathrm{CD}$ at age before 10 years [18]. None of these classifications are evidence based for the dynamics of linear growth.

The smaller number of female patients with prepubertal disease onset in our study most likely reflects the wellknown later onset of CD in females in this age group [19], and was the reason why a comparison of height was not possible. However, on comparing pooled standardized final heights, we could show that all patients with prepubertal onset of CD attained a significantly smaller final height compared with that of patients with later disease onset. Furthermore, univariate regression analysis identified age at diagnosis as the only predictive factor for adult height of CD patients. No difference in final height was found in patients with $\mathrm{UC}$, in agreement with the results of other studies [2].

Corticosteroids were administered in all age groups, with no statistical difference. Yet, the relevant doses, that is the cumulative dose administered per kilo body weight before the beginning of, or during the growth spurt, was not available for analysis. However, there has always been a controversy on the impact of corticosteroids on 
Table 3 Predictive factors for final height in patients with IBD according to the age class at disease onset

\begin{tabular}{|c|c|c|c|c|c|c|c|c|c|}
\hline \multirow[b]{2}{*}{ Outcome: standardized height } & \multicolumn{3}{|c|}{ Male CD patients } & \multicolumn{3}{|c|}{ Female CD patients } & \multicolumn{3}{|c|}{ All CD patients } \\
\hline & Estimated effect size & $95 \% \mathrm{Cl}$ & $P$-value & Estimated effect size & $95 \% \mathrm{Cl}$ & $P$-value & Estimated effect size & $95 \% \mathrm{Cl}$ & $P$-value \\
\hline \multicolumn{10}{|l|}{ Age at diagnosis } \\
\hline Prepubertal & 0 (ref) & - & - & 0 (ref) & - & - & 0 (ref) & - & - \\
\hline Pubertal & 0.8 & $0.4-1.2$ & $<0.001$ & 0.6 & $-0.1-1.2$ & 0.075 & 0.7 & $0.4-1.0$ & $<0.001$ \\
\hline Adult & 0.7 & $0.3-1.0$ & $<0.001$ & 0.7 & $0.1-1.3$ & 0.028 & 0.7 & $0.4-1.0$ & $<0.001$ \\
\hline Surgery occurrence & 0.1 & $-0.1-0.3$ & 0.269 & -0.1 & $-0.3-0.1$ & 0.083 & 0.0 & $-0.2-0.1$ & 0.548 \\
\hline \multicolumn{10}{|l|}{ Initial disease location } \\
\hline Ileal & 0 (ref) & - & - & 0 (ref) & - & - & 0 (ref) & - & - \\
\hline Colonic & 0.0 & $-0.3-0.3$ & 0.967 & 0.0 & $-0.2-0.3$ & 0.825 & 0.0 & $-0.2-0.2$ & 0.839 \\
\hline Ileocolonic & 0.0 & $-0.2-0.3$ & 0.804 & 0.0 & $-0.2-0.1$ & 0.626 & 0.0 & $-0.2-0.1$ & 0.845 \\
\hline \multirow[t]{2}{*}{ Upper GI only } & 0.9 & $0.1-1.6$ & 0.026 & -0.9 & $-2.0-0.3$ & 0.132 & 0.3 & $-0.3-0.9$ & 0.373 \\
\hline & \multicolumn{3}{|c|}{ Male UC/IU patients } & \multicolumn{3}{|c|}{ Female UC/IU patients } & \multicolumn{3}{|c|}{ All UC/IU patients } \\
\hline Outcome: standardized height & Estimated effect size & $95 \% \mathrm{Cl}$ & $P$-value & Estimated effect size & $95 \% \mathrm{Cl}$ & $P$-value & Estimated effect size & $95 \% \mathrm{Cl}$ & $P$-value \\
\hline \multicolumn{10}{|l|}{ Age at diagnosis } \\
\hline Prepubertal & 0 (ref) & - & - & 0 (ref) & - & - & 0 (ref) & - & - \\
\hline Pubertal & 0.5 & $-0.6-1.5$ & 0.360 & 0.2 & $-1.0-1.4$ & 0.748 & 0.3 & $-0.4-1.1$ & 0.386 \\
\hline Adult & 0.3 & $-0.7-1.4$ & 0.507 & 0.1 & $-1.0-1.3$ & 0.810 & 0.2 & $-0.5-1.0$ & 0.530 \\
\hline Surgery occurrence & -0.1 & $-0.5-0.3$ & 0.620 & 0.1 & $-0.3-0.6$ & 0.519 & 0.0 & $-0.3-0.3$ & 0.903 \\
\hline \multicolumn{10}{|l|}{ Initial disease location } \\
\hline Proctitis & 0 (ref) & - & - & 0 (ref) & - & - & 0 (ref) & - & - \\
\hline Left-sided colitis & 0.0 & $-0.2-0.4$ & 0.976 & 0.0 & $-0.3-0.2$ & 0.750 & 0.0 & $-0.2-0.2$ & 0.796 \\
\hline Pancolitis & 0.1 & $-0.3-0.3$ & 0.560 & -0.1 & $-0.3-0.2$ & 0.656 & 0.0 & $-0.2-0.2$ & 0.969 \\
\hline
\end{tabular}

$\mathrm{CD}$, Crohn's disease; $\mathrm{Cl}$, confidence interval; IBD, inflammatory bowel disease; UC/IU, ulcerative colitis or IBD-unclassified; upper GI, upper gastrointestinal tract.

growth dynamics [19,20]. Treatment with biological agents played no role in the patient groups with prepubertal disease onset of our study as infliximab was authorized for paediatric patients only in 2007. Initial disease locations were not found to be different between age groups of patients with CD and had no impact on final height. Even though the cumulative lifetime requirements of perineal and resectional surgery, representing the severity and behaviour of the disease, were significantly higher in patients with prepubertal disease onset, mostly minor perineal surgery, the difference was not important enough to emerge a predictive factor.

This study has several limitations worth mentioning: first, our study is not population based. In Switzerland, many adult IBD patients are followed by gastroenterologists in private practice, especially patients with uncomplicated disease living in regions without easy access to university hospitals. Second, pubertal stages and bone ages of patients with prepubertal and pubertal diagnosis of IBD were not available, and some patients categorized as pubertal may still have been prepubertal, despite their age. Third, parental heights were not available, but instead and as useful, we compared patients' final heights with population-based height data of coeval healthy individuals.

In conclusion, by grouping patients according to ages relevant for growth dynamics, we could show that patients with CD diagnosed before the onset of growth spurt achieve a significantly lower final height than patients with later disease onset, independent of the initial disease location, need for surgery or corticosteroid use. Future studies should explore factors delaying or reducing the pubertal growth spurt in patients with a prepubertal diagnosis of $\mathrm{CD}$, such as the severity and the duration of the disease before the beginning of the growth spurt.

\section{Acknowledgements}

The study was supported by a research grant from the Swiss National Science Foundation grant (3347CO-108792, Swiss IBD Cohort). D.H., N.F. and C.B. carried out the study planning, data analysis, writing and revision. P.B., K.H., R.K., V.R., A.N., J.S. and S.S. carried out data collection and transfer to the registry. All authors read and approved the final manuscript.

\section{Conflicts of interest}

There are no conflicts of interest.

\section{References}

1 Motil KJ, Grand RJ, Davis-Kraft L, Ferlic LL, Smith EO. Growth failure in children with inflammatory bowel disease: a prospective study. Gastroenterology 1993; 105:681-691.

2 Markowitz J, Daum F. Growth impairment in pediatric inflammatory bowel disease. Am J Gastroenterol 1994; 89:319-326.

3 Kanof ME, Lake AM, Bayless TM. Decreased height velocity in children and adolescents before the diagnosis of Crohn's disease. Gastroenterology 1988; 95:1523-1527.

4 Alemzadeh N, Rekers-Mombarg LT, Mearin ML, Wit JM, Lamers CB, van Hogezand RA. Adult height in patients with early onset of Crohn's disease. Gut 2002; 51:26-29.

5 Sawczenko A, Ballinger AB, Savage MO, Sanderson IR. Clinical features affecting final adult height in patients with pediatric-onset Crohn's disease. Pediatrics 2006; 118:124-129.

6 Griffiths AM, Nguyen P, Smith C, MacMillan JH, Sherman PM. Growth and clinical course of children with Crohn's disease. Gut 1993; 34:939-943.

7 Ferguson A, Sedgwick DM. Juvenile onset inflammatory bowel disease: height and body mass index in adult life. BMJ 1994; 308:1259-1263. 
8 Vasseur F, Gower-Rousseau C, Vernier-Massouille G, Dupas JL, Merle V, Merlin B, et al. Nutritional status and growth in pediatric Crohn's disease: a population-based study. Am J Gastroentero/ 2010; 105:1893-1900.

9 Markowitz J, Grancher K, Rosa J, Aiges H, Daum F. Growth failure in pediatric inflammatory bowel disease. J Pediatr Gastroenterol Nutr 1993; 16:373-380.

10 Carrascosa Lezcano A, Fernández García JM, Fernández Ramos C Ferrández Longás A, López-Siguero JP, Sánchez González E, et al. Grupo Colaborador Español. Spanish cross-sectional growth study 2008. Part II. Height, weight and body mass index values from birth to adulthood. An Pediatr (Barc) 2008; 68:552-569.

11 Pittet V, Juillerat P, Mottet C, Felley C, Ballabeni P, Burnand B, et al. Swiss IBD Cohort Study Group. Cohort profile: the Swiss Inflammatory Bowel Disease Cohort Study (SIBDCS). Int J Epidemio/ 2009; 38:922-931.

12 Lennard-Jones JE. Classification of inflammatory bowel disease. Scand J Gastroenterol Suppl 1989; 170:2-6.

13 Silverberg MS, Satsangi J, Ahmad T, Arnott ID, Bernstein CN, Brant SR, et al. Toward an integrated clinical, molecular and serological classification of inflammatory bowel disease: report of a Working Party of the 2005 Montreal World Congress of Gastroenterology. Can J Gastroenterol 2005; 19 (Suppl A):5-36.
14 Federal Administration, Swiss Statistics, Swiss Health Survey 2006. Available at: http://www.bfs.admin.ch/bfs/portal/de/index/news/ publikationen.htm/?publicationID=3502 [Accessed 19 February 2009].

15 Tanner JM, Whitehouse RH. Clinical longitudinal standards for height, weight, height velocity, weight velocity, and stages of puberty. Arch Dis Child 1976; 51:170-179.

16 Sorkin J, Muller D, Andres R. Longitudinal change in the heights of men and women: consequential effects on body mass index. Epidemiol Rev 1999; 21:247-259.

17 Drøyvold WB, Nilsen TI, Krüger O, Holmen TL, Krokstad S, Midthjell K, Holmen J. Change in height, weight and body mass index: longitudinal data from the HUNT Study in Norway. Int J Obes (Lond) 2006; 30:935-939.

18 Levine A, Griffiths A, Markowitz J, Wilson DC, Turner D, Russell RK, et al. Pediatric modification of the Montreal classification for inflammatory bowel disease: the Paris classification. Inflamm Bowel Dis 2011; 17:1314-1321.

19 Gupta N, Bostrom AG, Kirschner BS, Ferry GD, Winter HS, Baldassano RN et al. Gender differences in presentation and course of disease in pediatric patients with Crohn's disease. Pediatrics 2007; 120:1418-1425.

20 Markowitz J, Grancher K, Kohn N, Lesser M, Daum F; The Pediatric 6MP Collaborative Group. A multicenter trial of 6-mercaptopurine and prednisone in children with newly diagnosed Crohn's disease. Gastroenterology 2000; 119:895-902. 